\title{
RESEARCH DIRECTIONS
}

\section{First-Year Undergraduate Student Expectations of two UK Chemistry Degree Programmes}

\author{
Dylan P. Williams ${ }^{1, *}$, Shane Lo Fan Hin² and Erlina ${ }^{1,3}$ \\ ${ }^{1, *}$ Department of Chemistry, University of Leicester, University Road, Leicester, LE1 7RH, UK. \\ 2Department of Chemistry, School of Life Sciences, University of Sussex, Sussex House, Falmer, \\ Brighton, BN1 9RH. United Kingdom \\ ${ }^{3}$ Department of Chemistry Education, Faculty of Teacher Training and Education, Tanjungpura \\ University, Pontianak, Indonesia
}

*Corresponding Author: dylan.williams@leicester.ac.uk

Keywords: Undergraduate; Chemistry; Year One; Student Expectations

\section{Abstract}

Recent work on student perceptions of skills development and engagement with different teaching and learning approaches have provided useful evidence bases for practitioners aiming to enhance the student learning experience. Although there has been some useful research on student expectations in non-STEM (Science, Technology, Engineering and Mathematics) disciplines, there remains an opportunity to measure and analyse the expectations of students in STEM disciplines, particularly chemistry. The aim of this study was to measure the expectations that first year undergraduate chemists have of the types of learning experiences that will be included in their degree programmes, the amount of time per week that they will devote to different aspects of study and the types of learning behaviours they will adopt. Data was collected using questionnaires deployed at the Universities of Leicester and Sussex in the $2017 / 18$ academic year. The study has shown that many students overestimate the amount of lecture based $(59 \%)$ and small group based $(57 \%)$ contact time they expect to have. Students appear to place a high value on the importance of feedback in the learning process but the proportion of students who agree they will read and act on feedback decreases over the course of the academic year. A number of factors feed into student reflections on the difference between expectation and reality including the quality of student life (e.g. quality of accommodation and social activities), valuefor-money concerns (e.g. the amount of contact time and the quality of teaching) and matters related to workload and learning support.

\section{Research Questions}

What types of learning experiences do new undergraduate students expect in a chemistry degree programme? How much time do new undergraduate students expect to be dedicated to different types of learning activities in a chemistry degree? How do student learning behaviours and attitudes change over the course of the first year of study?

\section{Background}

In order to accommodate the needs of learners who enter higher education with a wide variety of educational backgrounds, strategies used to support student learning in chemistry have undergone a transformation since the start of the $21^{\text {st }}$ century. Examples of this type of transformation include the adoption of approaches such as Team Based Learning (Evans, et al., 2016), Problem Based Learning (Overton, 2007; Ramstedt, et al., 2016) and innovations based on flipped approaches to teaching (Seery, 2015; Rau, et 
al., 2017). This transformation has been driven by improvements in access to higher education for all as well as the success of outreach and widening participation initiatives (Lord, et al., 2009; Pratt \& Yezierski, 2018). A significant literature exists on the impact of studentcentred approaches to learning chemistry on student performance (Freeman, et al., 2014), attitudes towards the subject as well as workplace skills development (Galloway, 2017) and graduate outcomes (Hanson \& Overton, 2010). Literature also exists on the expectations STEM (science, technology, engineering and mathematics) students have of their own performance in their degree programmes (Hall \& Sverdlik, 2016). In spite of this work in related areas, very little literature exists on the initial expectations that new STEM undergraduate students have of their programmes of study and how these expectations align with the reality they experience in their first year at university (Hulme \& De Wilde, 2014).

Gaining an insight on the expectations undergraduate students have of their chosen degree programmes could potentially allow for the development of learning experiences and support mechanisms to facilitate the transition to university and allow them to develop their skills and abilities throughout their programmes of study. The expectations students have of a programme of study are influenced by a range of different factors including their perception of a 'value-formoney' learning experience, their attitudes towards different types of learning environment and experience and their career aspirations (Kandiko \& Mawer, 2013).

Recent studies on student expectations of higher education have emphasised the importance of 'value-for-money', timetabling of sessions sympathetic of the diversity of student needs and opportunities to work in peer learning groups (Hulme \& De Wilde, 2014; Money, et al., 2017). Previous work in other disciplines has shown that student expectations can be highly varied and the degree of alignment of these expectations with the reality experienced on arrival at university can influence the degree of satisfaction students have with their programmes of study (Byrne, et al., 2012) and unrealistic student expectations may result in student disengagement (Rowley, et al., 2008). Experiences of higher education that do not meet student expectations may motivate students to transfer to different programmes or withdraw from higher education (Byrne, et al., 2012). A 2013 Quality Assurance Agency commissioned study (Kandiko \& Mawer, 2013) into student perceptions and expectations of higher education in the UK highlighted the development of a 'consumerist ethos', where students may seek out programmes which offer a high level of perceived value-for-money. This focus on value-for-money may influence students' expectations of the number and type of contact hours they will receive as part of their education.

These insights on the expectations of undergraduate students in other disciplines informed the key research questions addressed in this paper: what types of learning experiences do new undergraduate students expect in a chemistry degree programme, how much time do these students expect to dedicate to different types of learning activities and how do learning behaviours and attitudes change over the course of the first year of study?

\section{Data Collection}

A questionnaire was developed to measure year one student expectations of the types of learning activities they expected to encounter in their chemistry degree programmes (as shown in Table 1) and the amount of time they expected to dedicate to these different learning experiences. The questionnaire also asked students to state a level of agreement with a range of statements based on different types of learning behaviours and attitudes. The questionnaire was designed and piloted with a small group of student volunteers in the summer of 2017 . The questionnaire was used to collect data from students at the University of Leicester at the start of the 2017/18 academic year.

For each of the learning activities shown in Table 1 students were asked to state their level of agreement with the following statement '/ expect my course to include a significant amount of this activity'. Responses were given 


\begin{tabular}{l} 
Type of learning activity \\
Memorising facts and information \\
Application of understanding \\
Calculations \\
Applications of chemistry to real-world problems \\
Opportunities to be creative \\
Opportunities to communicate science verbally \\
\hline Short problem solving (e.g. problems that take less than an hour) \\
\hline Long problem solving (e.g. problems that may take days or weeks) \\
\hline Teamwork
\end{tabular}

Table 1 List of learning activities included in this study

Type of learning behaviour
Attendance of all lectures is very important
Attendance of all laboratory sessions is very important
Studying at University will be very different to school/college
I must be more of an independent learner than ever before
Getting feedback on my work is an important part of learning
I will read all written feedback my tutors give me
I will take action based on the feedback I get from tutors
Discussing chemistry with other students is an important part of learning

Table 2 List of learning behaviours and attitudes included in this study

on a five point Likert scale (Strongly agree, agree, neutral, disagree and strongly disagree). In a separate question, students were asked 'Please state how strongly you agree with each of the following statements' related to learning behaviours and attitudes (see Table 2). Student responses to this question were given on the same five point Likert-type scale as the previous question.

The final question asked students to state 'How many hours per week do you expect to spend on the following learning activities: Private study, Attending lectures, Attending small group sessions and Attending laboratory sessions'. For each of these learning experiences, students were asked to choose from the following options: 5 or less hours, 610 hours, $11-15$ hours, $16-20$ hours or 20 or more hours.

An adapted version of this question was issued to the same cohort at the end of the 2017/18 academic year to measure the change in level of agreement with the learning behaviour and attitude statements. This adapted version included only the question on the different types of learning behaviours and attitudes and the wording was changed to reflect the fact that students were being questioned on their behaviour over the past academic year. The project and the research questionnaires received approval from the University of Leicester University Ethics Sub-Committee for Science and Engineering and Arts and Humanities in summer 2017.

In order to compare the behaviours and attitudes of Leicester students with those of another university, modified versions of the questionnaires was distributed to students on the chemistry degree programmes in the School of Life Sciences at the University of Sussex. Due to the focus of this part of the study, these versions of the questionnaire only included the Likert question on learning attitudes and behaviours. These questionnaires were used to collect data at the start and end of the 2017/18 academic year. The Sussex end of year questionnaire also included free-text response questions to provide some qualitative context to assist in the interpretation of the responses (see Table 3). The project and the research questionnaires 
Free text questions

Describe three things about the first year of your degree which have met your original expectations of university study

Describe three things about the first year of your degree which did not meet your original expectations of university study

Table 3 Free text questions used at the University of Sussex

\begin{tabular}{|l|c|c|}
\hline Questionnaire & Questionnaire responses & Total class size \\
\hline Leicester, start of year & $90(89 \%)$ & 101 \\
\hline Sussex, start of year & $85(100 \%)$ & 85 \\
\hline Leicester, end of year & $65(72 \%)$ & 90 \\
\hline Sussex, end of year & $27(35 \%)$ & 77 \\
\hline
\end{tabular}

Table 4 Response rates of different questionnaire cycles

were approved by the Sciences \& Technology Cross-Schools Research Ethics Committee.

In order to maximise response rates, printed copies of the questionnaire were distributed in sessions where attendance was required. All respondents were studying $\mathrm{BSc}$ or $\mathrm{MChem}$ chemistry degree programmes. Table 4 shows the response rates received from students for each questionnaire.

\section{Results and Discussion}

\section{Student expectations of types of learning experiences}

The expectations that Leicester chemistry students (during induction week) had of the types of learning activities that would make significant contributions to their chemistry degree programmes are shown in Figure $1(n=$ 90). The level of agreement is defined as the percentage of respondents who wither agreed or strongly agreed that their programmes would include a significant amount of each of the listed learning activities.

The level of agreement with all but two of the statements was greater than $80 \%$ which may reflect the effectiveness of promotional activities (e.g. applicant visit days, outreach events as well as printed and online promotional materials) at highlighting the role of these activities in chemistry degree programmes. The two statements that had agreement levels below $80 \%$ were Opportunities to be creative (50\% agreement) and Opportunities to communicate science verbally ( $74 \%$ agreement). It is known that first year chemistry undergraduate students tend to have a low appreciation of the importance of transferable skills (including creativity and oral communication) at the early stages of their studies when compared to their perception of the importance of discipline specific skills (Williams \& Lo Fan Hin, 2017). It is possible that the use of Context and Problem Based Learning (C/PBL) based outreach and visit day activities may increase student expectations that learning activities which promote development of transferable and problem solving skills form an integral part of chemistry degree programmes.

C/PBL approaches (Overton, 2007) form an integral part of the chemistry degree programmes taught at the University of Leicester and this approach to teaching is extensively publicised in printed literature (e.g. the programme brochure and the institutional prospectus), in online promotional materials (i.e. the University's Study web pages ${ }^{1}$ ) and at visit days for applicants (where visitors participate in small scale C/PBL activities). In spite of this, it appears a significant number of

${ }^{1}$ Further details of the University of Leicester's online promotional materials for chemistry applicants can be found at https://le.ac.uk/chemistry/study 
First-Year Undergraduate Student Expectations of two UK Chemistry Degree Programmes

I expect my course to include a significant amount of the following... $(n=90)$

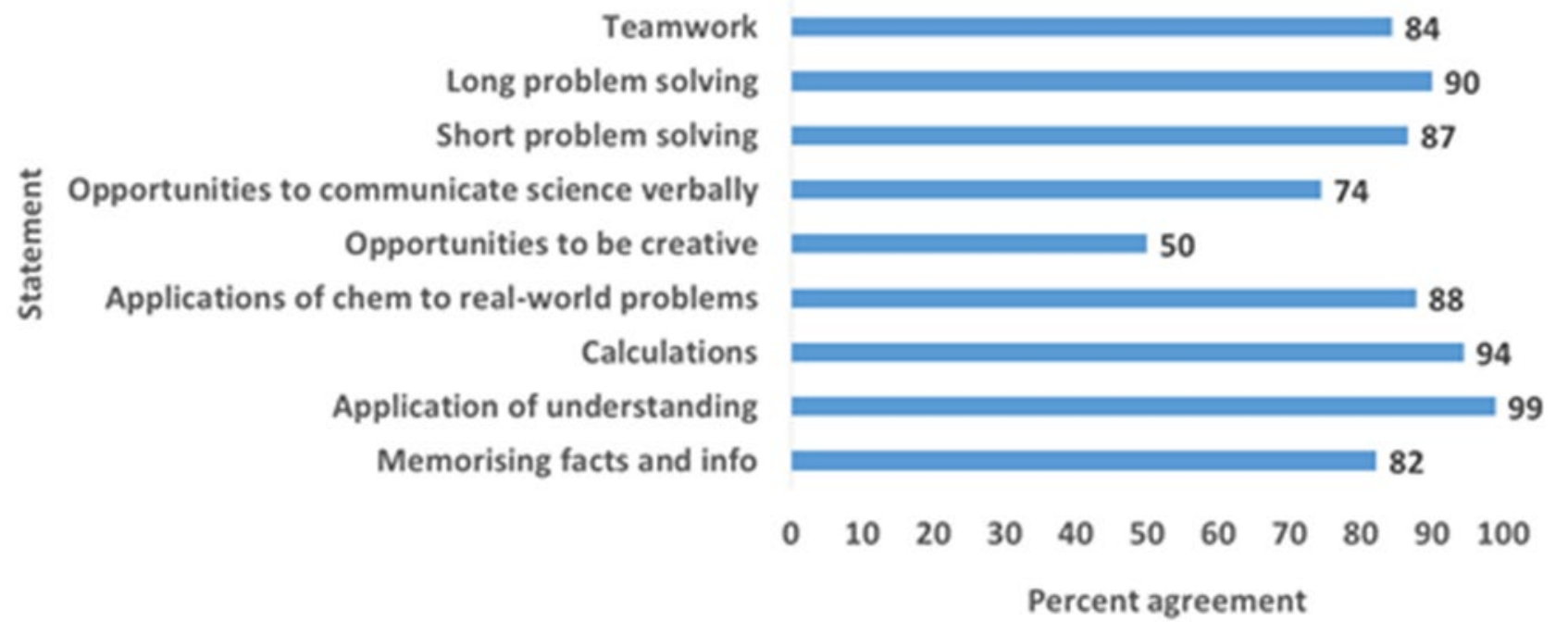

Figure 1 Level of agreement of year one chemistry students in induction week that their chemistry course will include the listed learning activities $(n=90)$.

new chemistry students do not expect learning activities based on creativity or verbal communication of science to form integral part of chemistry degree programmes.

In order to familiarise students with these types of experiences and to emphasis the key differences between learning chemistry at higher education levels, a C/PBL induction activity has been developed and embedded in the opening weeks of year one (Williams, 2017). This activity has been designed to promote student awareness of the importance of verbal communication of scientific topics and to encourage students to use their chemical skills and understanding in a creative way by designing and piloting a novel learning resource.

\section{Student expectations of learning behaviours}

In order to measure the extent of change of chemistry student learning behaviour over the course of their first year of study, respondents were asked to state their level of agreement with a series of statements based on learning behaviours or attitudes (see Table 2). The same question was asked at the beginning of the 2017/18 academic year at both the Universities of Leicester and Sussex. Figure 2 shows the initial responses from both student groups (Sussex $(n=85)$ in red and Leicester
( $n=90)$ in blue) expressed as percentages of students who agree or strongly agree with each of the statements. It can be seen that the level of student agreement is consistently high at this opening stage of the degree programmes. This may be due to the initial enthusiasm that students have for their new programmes. The lowest level of agreement was reported for the response to the statement Discussing chemistry with other students is an important part of learning from students at Leicester (83\% agreement) which may be due to the low importance some students place on oral communication skills at this stage of their degree as discussed in the previous section.

The question was repeated with both student groups at the end of the 2017/18 academic year ( $n=65$ at Leicester and $n=27$ at Sussex) and the differences between the initial and final levels of agreement for the two student groups are reported in Figure 3 (Sussex in red and Leicester in blue). Although it can be seen that most levels of agreement decreased over the course of the first year of study, only five of the statements showed changes of over $5 \%$ : Attendance of all lectures is very important; Attendance of all laboratory sessions is very important; I must be more of an independent learner than ever before; I will read the written feedback my tutors give me; I will take action based on the feedback I get from tutors. 
First-Year Undergraduate Student Expectations of two UK Chemistry Degree Programmes

\section{I agree/strongly agree with the following statements}

Discussing chemistry with other students is an important part of learning

I will take action based on the feedback I get from tutors

I will read the written feedback my tutors give me

Getting feedback on my work is an important part of learning

I must be more of an independent learner than ever before

Studying at uni will be $v$ different to school/college

Attendance of all lab sessions is $v$ important

Attendance of all lectures is $v$ important
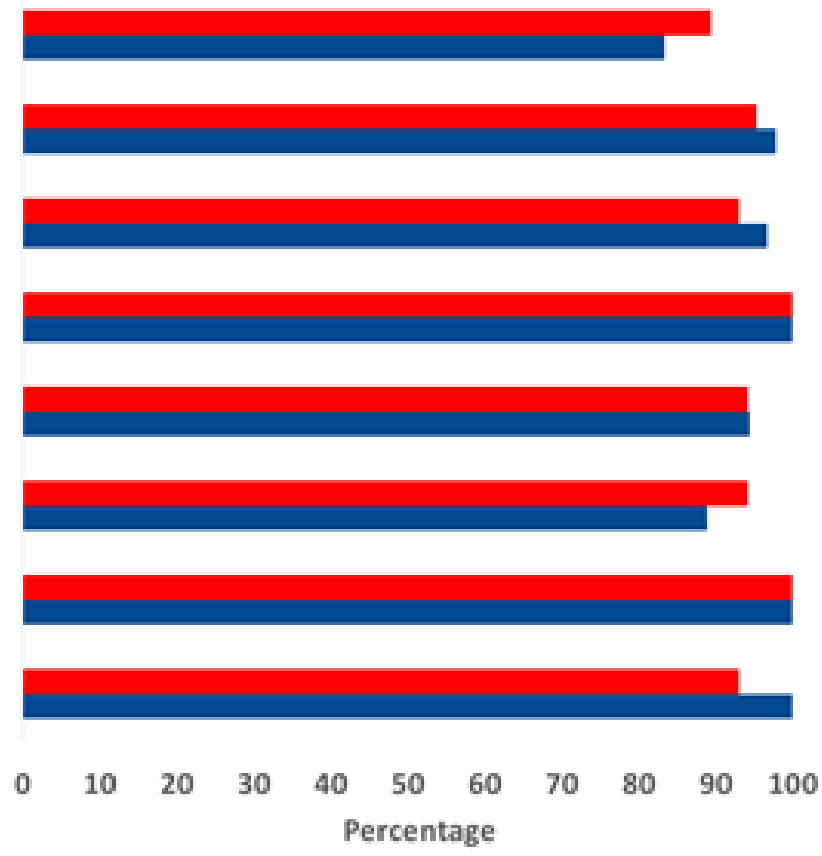

- Sussex $\mathbf{m}$ Leicester

Figure 2 Level of agreement of year one chemistry students at Sussex (red, $n=85$ ) and Leicester (blue, $n=90$ ) with the listed statements related to learning behaviours and attitudes at the start of the 2017/18 academic year.

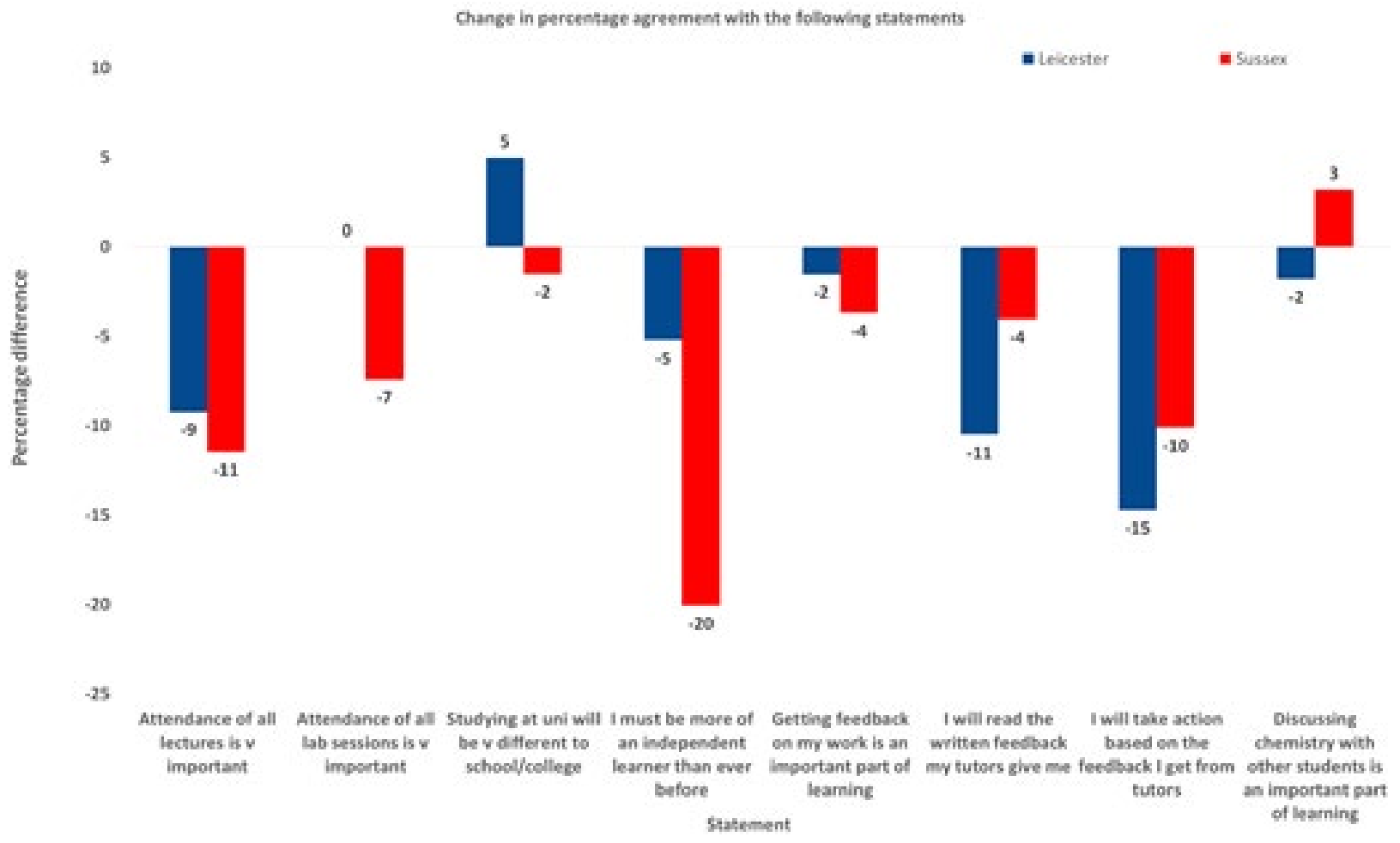

Figure 3 Change in level of agreement (as percentage) of year one chemistry students at Leicester (blue, $n_{\text {start }}=90, n_{\text {end }}=65$ ) and Sussex (red, $n_{\text {start }}=85, n_{\text {end }}=27$ ) with the listed statements related to learning behaviours and attitudes at the start of the 2017/18 academic year. 
The decrease in the level of agreement with the statements on lecture and laboratory attendance appears to reflect the decrease in attendance observed in teaching sessions at both institutions towards the end of year one of the respective programmes. The fact that the decrease in level of agreement with the statement on lecture attendance is greater than that observed for the statement on laboratory attendance is perhaps unsurprising as there is a minimum laboratory attendance threshold in place in both institutions and failure to achieve this minimum standard can result in failure of the practical module and potential course termination.

There is a decrease in level of agreement with two of the statements related to feedback from respondents at both institutions: I will read the written feedback my tutors give me $(11 \%$ decrease at Leicester and a 5\% decrease at Sussex) and I will take action based on the feedback I get from tutors $(15 \%$ decrease at Leicester and $10 \%$ decrease at Sussex). Creating assessment structures which allow students to appreciate the importance of feedback as an integral tool in personal development is a sector-wide challenge (this is reflected in the responses to questions on feedback in the UK sector-wide National Student Survey). Responses to the statement Getting feedback on my work is an important part of learning only changes by a small degree over the course of the year (a $2 \%$ decrease at Leicester and a 4\% decrease at Sussex). This data suggests that this drop-off in student engagement with feedback may occur at a very early stage of the university experience in spite of the fact that students recognise the importance of feedback. It may be valuable to place a greater emphasis on how students can use feedback effectively to develop their skills and understanding at the very early stages of university education (e.g. during induction) with some reinforcement throughout the academic year. The mechanisms used to provide feedback may also be an important factor in determining student engagement levels (e.g. the use of multimedia formats for feedback (McGarvey \& Haxton, 2011)).

The largest single change in response was the response to the statement I will need to be more of an independent learner than ever before from Sussex students (20\% decrease). The level of agreement of Leicester respondents with this statement also decreased but by a smaller absolute amount ( $5 \%$ decrease). There are no statistically significant differences between the responses to this statement in the initial or final questionnaires from students at the two institutions $(p<0.05)$. It is worth noting that a difference student response to this statement might have been expected due to differences in the teaching and learning approaches adopted in the different universities. The University of Leicester makes use of the openended, C/PBL approach in the early stages of year one of its chemistry degree programmes. This is a student-centred approach that many students have not encountered prior to this stage of their education (Williams, et al., 2010). Students at the University of Sussex are also exposed to the C/PBL approach but this occurs after year one so the learning experiences they encounter in their first year of study may be more closely aligned to their experiences at level 4.

\section{Student expectations of study time at university}

Students at the University of Leicester were asked to state the expected amount of contact time (in hours per week) they would be expected to spend on four key learning activities:

Private study (including revision, doing tutorials and writing lab reports), Attending lectures, Attending laboratory sessions and Attending small group sessions (including tutorials and $C / P B L$ sessions). The results are summarised in Table 5. In spite of the fact that the University of Leicester advertises the appearance of a 'typical' timetable at applicant visit days, the majority of students had higher expectations of study time spent on two out of the three types of timetabled activity than that provided on the course. A total of $59 \%$ of respondents overestimated the number of lecture based contact hours per week and $57 \%$ of respondents overestimated the amount of contact time devoted to small group study sessions per week. This is perhaps a reflection of both the high expectations that students have of what constitutes a value-for-money experience and the student perception that the 
First-Year Undergraduate Student Expectations of two UK Chemistry Degree Programmes

\begin{tabular}{|l|c|c|c|c|c|}
\hline & $\begin{array}{c}5 \text { or less } \\
\text { hours }\end{array}$ & $6-10$ hours & $\begin{array}{c}11-15 \\
\text { hours }\end{array}$ & $\begin{array}{c}16-19 \\
\text { hours }\end{array}$ & $\begin{array}{c}20 \text { or more } \\
\text { hours }\end{array}$ \\
\hline Private study & 7 & 28 & 43 & 19 & 3 \\
\hline Attending lectures & 0 & 40 & 24 & 31 & 4 \\
\hline $\begin{array}{l}\text { Attending small } \\
\text { group sessions }\end{array}$ & 42 & 50 & 2 & 4 & 1 \\
\hline $\begin{array}{l}\text { Attending laboratory } \\
\text { session }\end{array}$ & 43 & 44 & 4 & 8 & 0 \\
\hline
\end{tabular}

Table 5 Student expectations of weekly study hours required for different learning activities Expressed as a percentage $(n=90)$.

lecture theatre still plays a dominant role in University chemistry education (perhaps reinforced by experiences at school and further education level). A total of $87 \%$ of students expected to spend up to 8 hours of contact time per week in the teaching laboratory which is consistent with the first year teaching laboratory experience at Leicester (where students do either four or eight hours of laboratory per week). The fact that student expectations of laboratory contact time were more closely aligned with reality that their expectations of other types of contact time may reflect the very limited experience of laboratory chemistry that some students have when they arrive at university. This may mean some students highly value laboratory contact (perhaps more so than time spent in other types of contact session).

\section{Student feedback on experiences and expectations}

Students at the University of Sussex were asked to discuss the aspects of their first year that has met or failed to meet their initial expectations $(n=27)$. This data was collected as part of the questionnaire distributed at the end of the academic year and, in order to generate an overview of all factors that impacted on the student first year experience, respondents were told not to limit their responses to course related matters. Analysis of the student comments revealed four primary themes: Student life, Learning experience, Assessment and Learning support.

\section{Student Life}

One basic theme that was highlighted in a number of student responses was the treatment of students by staff (and the institution). It was clear that students expected to be treated as adults and in all cases where this was mentioned, this expectation had been met ("Treated like an adult, not babied by lecturers" and "Tutors treat me like an adult"). Some of the negative aspects of the student first year experience reported in these responses were due to factors outside of the immediate control of their host department (e.g. the quality of accommodation, the fact that the host university charges for printing and matters related to timetabling of sessions). It is interesting to note that student concerns about these factors are consistent with previously reported findings (Kandiko and Mawer, 2013) that students expect a 'value-for-money' university experience so the quality of accommodation and institutional support mechanisms may be as important as concerns related to the specific programme of study such as the amount of contact time ("Shorter term time and contact hours than expected"). Some students also commented that the timetable structure did not necessarily meet their expectations (e.g. 'large gaps between lectures or very late lectures/workshops') which may be a barrier to engagement for students with caring needs or part-time employment commitments.

\section{Learning experience}

Workload and stress levels were recurring themes in student responses to these free-text questions. It is interesting to note that a number of students stated that their experiences of high workloads and high stress levels met their initial expectations ("There is a greater workload than there was in school" and "Quite a bit of stress"). The analysis of the qualitative responses also revealed that the enthusiasm of 
teaching staff and the level of enjoyment students get from the subject are significant factors in judging whether experience meets expectation. (Students indicate that they expect an interesting and engaging programme.) Some responses highlighted a lack of consistency in the way material was presented by staff ("Not all lecturers are of the same standard") which may be a factor which impacts on student satisfaction.

It is worth noting that level of difficulty of the programme was commented on repeatedly. The most common response type was that the programme was easier than the initial expectation ("A lot of recurring A-level knowledge, and "I thought it would be harder" and "Thought it would be a bit more challenging") although some students felt that the level of difficulty of some teaching had met their initial expectations ("The difficulty levels of some modules have met my expectations (i.e. by going beyond A-level)"). This mixed response to the level of difficulty of the course is likely to be a reflection of the heterogeneous student intake with each individual student having a unique learning background.

\section{Assessment and Learning support}

Some students reported that they expected to receive printed copies of course materials (another possible contributing factor to a 'value-for-money' experience) and feedback on all examinations. Students expected a diverse range of assessments with the laboratory component of the programme making a more significant overall contribution to their assessment than it had in earlier stages of their education. This may be a reflection of the fact that many students appreciate that they will have much more access to a laboratory environment during their time at university than they had in earlier stages of university life. This expectation may also be influenced by students' views on the professional skills development required to be a practicing chemist.

\section{Conclusions}

Questionnaire data has revealed that first year chemistry undergraduate students have lower initial expectations of learning experiences which allow them to verbally communicate their understanding of the subject or to be creative than may have been expected. Students appear to retain a strong appreciation of the importance of feedback as part of the learning process but the level of agreement that students will read and act on feedback decreases over the course of the first year of study. The majority of students at the University of Leicester overestimated the amount of time they would spend in contact sessions based on lecture and small-group learning experiences but the majority of students correctly estimated the approximate number of hours of time spent in the teaching laboratory per week. Qualitative data collected at the University of Sussex revealed a number of factors that students consider when reflecting on the expectation-reality gap at the end of year one. Chemistry student expectations of value-for-money result in reflections which focused on the amount of contact time, the quality of teaching and the level of teaching. Many questionnaire respondents appreciated the fact university study is a 'step-up' from further education and that university chemistry study involves a greater workload than they had previously experienced.

\section{Acknowledgements}

Thanks go to Dr Richard Blackburn for proof reading this paper and Dr Barbara Villa Marcos for help with distribution of the questionnaires in laboratory sessions at the University of Leicester.

\section{References}

Byrne, M., Flood, B., Hassall, T., Joyce, J., Arquero Montaño, J.L., González González J., M. \& Tourna-Germanou, E. (2012), Motivations, expectations and preparedness for higher education: A study of accounting students in Ireland, the UK, Spain and Greece. Accounting Forum, 36, 134-144 DOI: 10.1016/j.accfor.2011.12.001

Evans, H.G., Heyl, D.L. \& Liggit, P. (2016), Team-Based Learning, Faculty Research, and Grant Writing Bring Significant Learning Experiences to an Undergraduate Biochemistry Laboratory Course. Journal of Chemical Education, 93, 1027-1033 DOI: 10.1021/acs.jchemed.5b00854. 
Freeman, S., Eddy, S.L., McDonough, M., Smith, M.K., Okoroafor, N., Jordt, H. \& Wenderoth, M.P. (2014), Active learning increases student performance in science, engineering, and mathematics. Proceedings of the National Academy of Sciences, 111, 84108415 DOI: $10.1073 /$ pnas. 1319030111.

Galloway, K.W., (2017), Undergraduate perceptions of value: degree skills and career skills. Chemistry Education Research and Practice, 18, 435-440 DOI: 10.1039/C7RP00011A.

Hall, N.C. \& Sverdlik, A. (2016), Encouraging Realistic Expectations in STEM Students: Paradoxical Effects of a Motivational Intervention. Journal, 7, 1109.

Hanson, S. \& Overton, T.L. (2010), Skills required by new chemistry graduates and their development in degree programmes. Hull, United Kingdom: UK Physical Sciences Centre, Higher Education Academy.

Hulme, J.A. \& De Wilde, J. (2014), Tackling transition in STEM disciplines: Supporting the Science, Technology, Engineering and Mathematics (STEM) student journey into higher education in England and Wales. York: Higher Education Academy.

Kandiko, C.B. \& Mawer, M. (2013), Student Expectations and Perceptions of Higher Education: Executive Summary. London King's Learning Institute.

Lord, P., Straw, S., Hart, R., Springate, I. \& Harland, J. (2009), Evaluation of Chemistry for our Future: Extension Phase Report. National Foundation for Educational Research, Slough.

McGarvey, D.J. \& Haxton, K.J. (2011), Using audio for feedback on assessments: Tutor and student experiences. New Directions in the Teaching of Physical Sciences, 5. DOI: 10.29311/ndtps.v0i7.459.

Money, J., Nixon, S., Tracy, F., Hennessy, C., Ball, E. \& Dinning, T. (2017), Undergraduate student expectations of university in the United Kingdom: What really matters to them? Cogent Education, 4, $1301855 . \quad$ DOI: 10.1080/2331186X.2017.1301855.
Overton, T. (2007), Context and problembased learning. New Directions in the Teaching of Physical Sciences, 6. DOI: 10.29311/ndtps.v0i3.409.

Pratt, J.M. \& Yezierski, E.J. (2018), Characterizing the Landscape: Collegiate Organizations' Chemistry Outreach Practices. Journal of Chemical Education, 95, 7-16. DOI: 10.1021/acs.jchemed.7b00627.

Ramstedt, M., Hedlund, T., Björn, E., Fick, J. \& Jahnke, I., (2016), Rethinking chemistry in higher education towards technologyenhanced problem-based learning. Education Inquiry, 7, 27287. DOI: 10.3402/edui.v7.27287.

Rau, M.A., Kennedy, K., Oxtoby, L., Bollom, M. \& Moore J.W. (2017), Unpacking "Active Learning": A Combination of Flipped Classroom and Collaboration Support Is More Effective but Collaboration Support Alone Is Not. Journal of Chemical Education, 94, 14061414. DOI: 10.1021/acs.jchemed.7b00240.

Rowley, M., Hartley, J. \& Larkin, D. (2008), Learning from experience: the expectations and experiences of first-year undergraduate psychology students. Journal of Further and Higher Education, 32, 399-413. DOI: $10.1080 / 03098770802538129$.

Seery, M.K., (2015), Flipped learning in higher education chemistry: emerging trends and potential directions. Chemistry Education Research and Practice, 16, 758-768. DOI: 10.1039/C5RP00136F.

Williams, D.P. (2017), Learn on the Move: $A$ Problem-Based Induction Activity for New University Chemistry Students. Journal of Chemical Education. DOI: 10.1021/acs.jchemed.7b00399.

Williams, D.P. \& Lo Fan Hin, S. (2017), Measuring the Impact of Context and Problem Based Learning Approaches on Students' Perceived Levels of Importance of Transferable \& Workplace Skills. New Directions in the Teaching of Physical Sciences, 12. DOI: 10.29311/ndtps.v0i12.851

Williams, D.P., Woodward, J.R., Symons, S.L. \& Davies, D.L. (2010), A Tiny Adventure: the 
First-Year Undergraduate Student Expectations of two UK Chemistry Degree Programmes

introduction of problem based learning in an undergraduate chemistry course. Chemistry Education Research and Practice, 11, 33-42. DOI: 10.1039/C001045F. 